Int. J. Electrochem. Sci., 15 (2020) $11821-11832$

International Journal of

ELECTROCHEMICAL

SCIENCE

$\underline{\text { WWW.electrochemsci.org }}$

\title{
Preparation of NiP-WC Composite Coatings by Ultrasonically Assisted Electroless Plating and Their Characterization
}

\author{
Xing-Shou Zhang ${ }^{1}$, Qin-Ying Wang ${ }^{1, *}$, Yi-Rong Tang ${ }^{1}$, Hai-chang Guo ${ }^{2}, Y u$-chen Xi ${ }^{1}$, \\ Li-Jin Dong ${ }^{1}$, Huaibei Zheng ${ }^{3}$ \\ ${ }^{1}$ School of New energy and Materials, Southwest Petroleum University, Chengdu 610500, China \\ ${ }^{2}$ Department of Materials Science and Engineering, College of Engineering, Peking University, \\ Beijing 100871, China \\ ${ }^{3}$ State Key Laboratory of Marine Equipment Made of Metal Material and Application, Anshan \\ 114009, Chin \\ "E-mail: wangqy0401@126.com
}

doi: $10.20964 / 2020.12 .10$

Received: 7 April 2020 / Accepted: 7 June 2020 / Published: 31 October 2020

To improve coating properties, NiP-WC and NiP coatings have been prepared by ultrasonically assisted electroless plating and their performance after heat treatment has been studied. The surface micromorphologies of the coatings were analyzed, and it was shown that the size of the spherical microstructure of the ultrasonically assisted electroless NiP coating was reduced from $5 \sim 10 \mu \mathrm{m}$ to $2 \sim$ $5 \mu \mathrm{m}$. In addition, pure NiP and NiP-WC coatings with ultrasonic assistance showed $36 \%$ and $75 \%$ higher hardness than those without ultrasonic assistance and the hardness of the electroless coating after heat treatment was higher than that of the original electroless plating coating. The corrosion resistance of the NiP-WC and NiP electroless plating with ultrasonic assistance showed $18.46 \%$ and $52.12 \%$ higher $R_{p}$ value than those without ultrasonic assistance. The results show that ultrasonic assistance can increase the uniformity, hardness, and corrosion resistance of the coating.

Keyword: NiP-WC composite coating; Ultrasonically assisted electroless plating; Heat treatment; Hardness; Corrosion behavior

\section{FULL TEXT}

(C) 2020 The Authors. Published by ESG (www.electrochemsci.org). This article is an open access article distributed under the terms and conditions of the Creative Commons Attribution license (http://creativecommons.org/licenses/by/4.0/). 